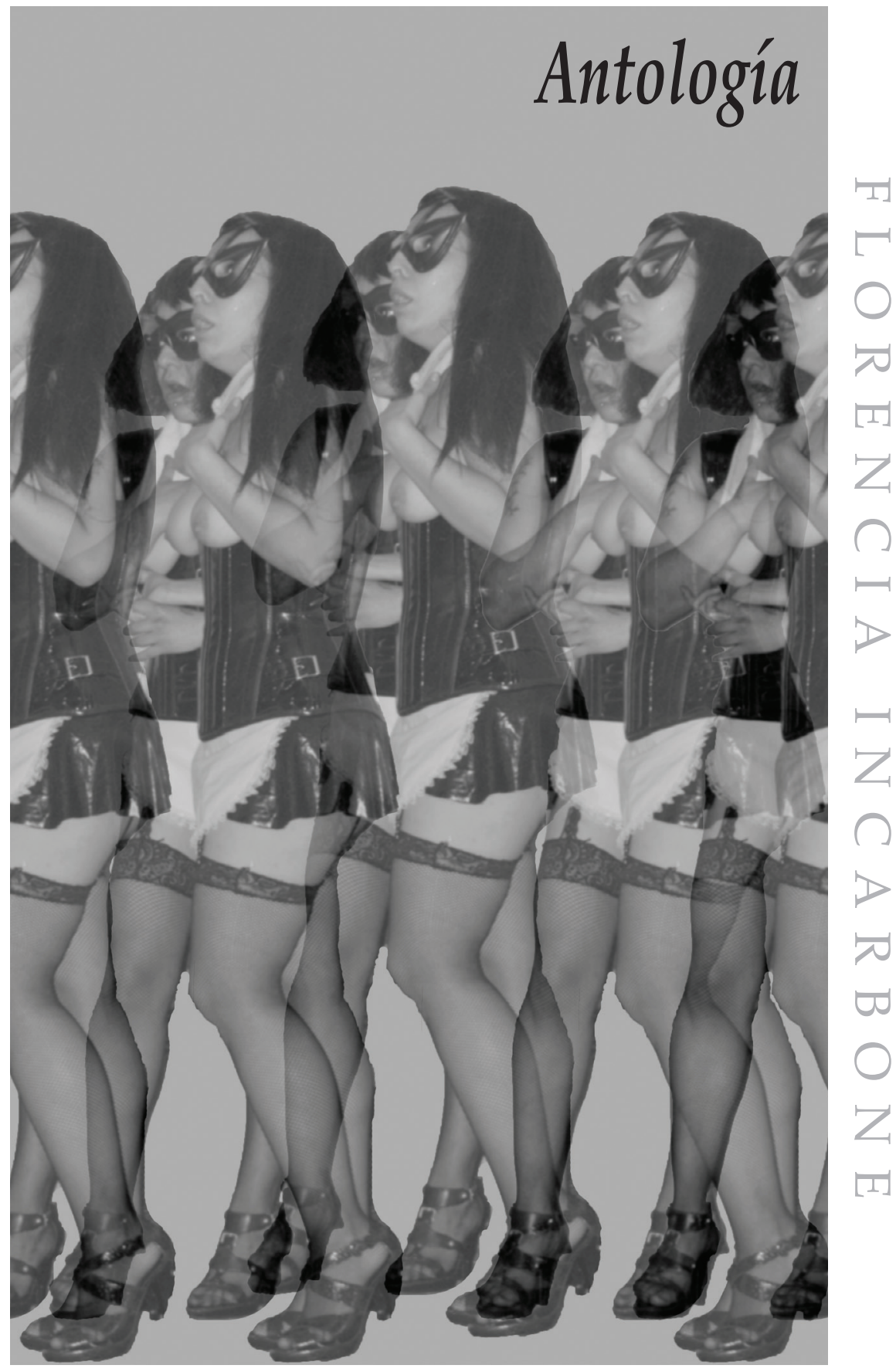





\title{
Releer a Elvira Hernández Antología poética
}

\author{
Karem Pinto \\ karempinto@yahoo.com \\ Ana María Baeza C. \\ ambaeza.carvallo@yahoo.es \\ Universidad de Chile
}

La poesía de Elvira Hernández (Lebu, 1956) se ha revitalizado por el interés de jóvenes poetas, jóvenes investigadores e investigadoras y estudiantes de literatura que se reconocen en ella y han actualizado su lectura, interesándose tanto por la vigencia del contenido crítico de su obra, como por la afirmación ética y estética representada por su figura personal, comprometida con los derechos humanos y con la función social del poeta.

Es así que durante 2012, miembros del colectivo Descentralización Poética, de la Corporación Cultural Balmaceda 1215, del colectivo Mal de Ojo y de varias editoriales emergentes, crearon una red de trabajo con el objetivo de impulsar la candidatura de la poeta al Premio Nacional de Literatura, iniciativa que fue acogida y apoyada por el Centro de Estudios Culturales Latinoamericanos y el Centro de Estudios de Género y Cultura en América Latina de nuestra Facultad de Filosofía y Humanidades. Esta instancia, ha servido para instalar y articular diversas reflexiones sobre la complejidad y los alcances de una poesía que conserva a través del tiempo una mirada aguda sobre la realidad chilena contemporánea.

Se trata de un proyecto coherente que interroga hasta la incomodidad nuestro pasado histórico, así como también la conflictividad 
de las identidades políticas, indígenas y genérico sexuales, creando un lenguaje singular a través de la experimentación que incorpora expresiones populares y topos contextualizados en la realidad nacional, pero que también son reconocibles más allá de nuestras fronteras, gracias a la pluralidad de sentidos que la poeta pone en juego.

Nos interesa entonces, visibilizar la trascendencia de la producción poética de Elvira Hernández y el lugar central que esta ocupa en el desarrollo de la poesía chilena de las últimas décadas. En ese panorama, La Bandera de Chile (1991) y Santiago Waria (1992) se han convertido en libros emblemáticos de los ochenta y noventa. Sin embargo, el reconocimiento académico y literario, y el valor que la crítica especializada le otorga a su escritura no se traduce en una adecuada circulación y recepción de su obra. Títulos como Meditaciones físicas por un hombre que se fue (1987), El orden de los días (1991) o Carta de viaje (1989) parecen sencillamente extraviados, no han sido reeditados y, por lo tanto, no son accesibles. En este sentido, la presente antología responde a la necesidad de hacer luz sobre un conjunto de textos poco conocidos que resulta indispensable releer para apreciar la contundencia y rigurosidad con que la poeta ha elaborado su propuesta escritural a lo largo de los años. Presentamos, además, algunos poemas de Cuaderno de deportes (2010), última publicación de la autora, la cual reúne una serie de escritos realizados desde 2004 y que se gestan al calor de un taller de poesía de tema griego que Elvira Hernández realizó en la Biblioteca Nacional.

Meditaciones físicas por un hombre que se fue. 1987 (Arte postal)

Cuando los días son todos iguales todos pegados unos a otros a otros todos por el mismo hilo dictatorial conocido ya nadie reconoce ya los horrores por sus horrores sino por su /vértebra

que vertebra la espalda para que vaya rota vaya al suelo entonces vamos de cuerpo entero saliendo de nuestras /concavidades

húmedos todavía amontonados cogidos por sus porciones /anudados 
anudados vamos reenganchados los huesos líquidos en su hervor la piel al estirarse hace un chasquido de hojas entre tus muslos los muslos huesosos como ríos crujen tibios entre lengua escurriéndose brillante gota a gota por los pliegues.

Carta de viaje. Buenos Aires: Eds. Último Reino, 1989.

Vean el escualo que monto

-la fiera figurada-

principianta ahí arriba

en mis faenas de pesca

encimera ahí

a horcajadas sobre ese pez mío

aletazo y aletazo

mancornados tocando tierra

$$
\begin{aligned}
& \text { él manco } \\
& \text { yo herma }
\end{aligned}
$$

el escualo que monto

como meteoro o granizo

posándose en la colosal losa

mi magnífico insecto

pone sus patas en el parking de aviones

silencia la torre de control

y ruedo por la escalerilla de sus dientes

hecha vómito y milagro

\&

Robinson Crusoe se acompañó de Viernes sus días. Hizo su juego toda la semana. A mí nadie me acompañará por esta tierra blanca donde el polvo es harina que cae del cielo.

Mi carromato se arrastrará en vano.

La brújula está dormida. 
Es la hora del lobo.

En blanco y negro el panorama de espacio y tiempo.

$$
\begin{aligned}
& \text { Yo herma } \\
& \text { cuchepa } \\
& \text { india sudamericana }
\end{aligned}
$$

No vuelvo a cruzar el Estrecho de Behring para devolverle la mano a nadie.

En esa blanca torta boreal no encontrarán la huella de mis extremidades.

No intento una plusmarca con las ruedecitas de mi trasero.

$$
\begin{gathered}
\text { No soy el Capitán Ávalos } \\
\text { No soy el Tiburón Contreras } \\
\text { Soy lengua ampollada por la } \\
\text { electricidad }
\end{gathered}
$$

Nunca estaré colgando de una lágrima del Everest Estoy sentada y me columpio en el sillar de mi pelvis el filo del mundo.

$\&$

Vengo del País de los Vertederos Eternos, del Aerosol Templado, de los Montes de Piedad haciendo nata. Flora y Fauna Travesti largándose por el larguero de tierra sableada. Despeñados por la Montaña Rusa nuestros sesos lloran Edén y Landia, Cielo y Tierra.

$$
\text { Y, ¡héme aquí en el lobby del Viejo Mundo! }
$$

Atrás quedaron los Piececitos Azules en la Feria Persa

y Coreana. 
$\&$

“Con buen tiempo, el 12 de octubre de 1987 he cruzado la frontera"

Patagona levanto las tolderías de mi esterilidad.

Desayuno albatros de Nueva Zelandia y lo que caiga

a mi olla.

Chincol o jote

Ese es el impasse

El horizonte de una mañana desierta.

Vengo del País del Reloj de Flores, de Tres y Cuatro Álamos. Vengo de vuelta del "Fausto" y he buscado todos estos años a Juan Alacalufe Desaparecido.

En mi sentimental journey, la búsqueda del Amor Imposible. Son mis mutilaciones las que toman asiento en la yacija del rodado y como un centauro chirriante me precipito dando tumbos por la rectitud de la tundra.

Cuesta dar en el blanco.

La página esteparia no cede al manoseo de la callosidad.

La página no es pasamano ni pasatiempo ni baranda para niños.

La página del vacío aparente viene escrita sólo hay que tactar.

Y tú, al otro lado del mundo, más allá de las Columnas de Hércules, fácilmente ubicable por ENTEL, por un misil tierra-a-tierra, por un satélite de comunicación, por un Correo-Amigo ¿dónde estás? 
$\&$

\section{NO ENTER}

Avanzo por Nueva Limay en dirección Este ortigada a contrapelo por mis escamas

-la sarna de los viajesvoy orillando la plataforma de despegue

\section{NO FUCK}

Los yuyos están altos

Blue Velvet "el colchón de la novia"

No te oigo

el viento blanco se come tu voz

A cuestas en mi cuerpo va mi traje especial un tejido azul de cicatrices el abrigo pedregoso de los años ¡Me reconocerás!

He traspasado la Puerta de San José y trepo La Tribuna Numerada de los nichos

1.564.381

Se ha iniciado la cuenta regresiva a la velocidad de la luz.

(el sol como un ícaro se precipita al mar)

La procesión va por fuera y a ojos vista.

Las lágrimas brillan como cápsulas de cianuro. Las cabezas caen cortadas al rape.

NO BOTE BASURA 
(automáticamente las compuertas se cierran)

En el confín del mundo, donde nada nos distinguirá de nada que los trolls nos protejan

El orden de los días. Roldanillo, Colombia: Eds. Embalajes del Museo Rayo, 1991.

DÍA 1

a alguien le parece que sale el sol una luz cruza como una cuchillada el relámpago matutino del filamento despiadado pone una herradura incandescente

quién madruga amanece más insomne marcado viaja con la fosforecencia solar como un golpe con la cicatriz visible del alarma clock en el entrecejo

el día se destripa encima y hay que ponerle el hombro para cargarlo

DÍA 3

alguien camina para comprar pan no comprende que pueda llevar los pies amasados es la mañana es la vejez

el pan oscila en la balanza como nalgas húmedas dan su precio high quality en el visor automático que registra los dedos que lo tocaron nunca se verán 
el pan se quema con sólo mirarlo brillante se marcha en una bolsa de nailon puede ir hasta un museo

la cara de Dios no da la cara será mendrugo será sopa cara una mejilla desvencijada

subieron el pan en dos pesos

DÍA 7

un hombre es inmovilizado por tres tipos lo golpean con pedazos de risa con pedazos de fierro el hombre grita a nadie ¿sálvenme! nadie será testigo en una calle le borran la boca los ojos con scotch todavía hay luz diurna ortogonal no luminarias el carabinero de la esquina bosteza hacia los cielos el hombre sube la piso de un taxi como un choapino ponen los pies sobre él cierran las puertas el taxi se pierde entre los autos con la banderilla LIBRE desde la ventana de las micros asoman rostros lámparas extinguidas

\section{NOCHE LARGA}

abierta el cuadrante de la noche la noche más ancha más extrema desabotonada de los meridianos un odre filtrando un ojo que lagrimea nadie hay en la arista opada que la noche 
la noche la con cavidad oscura que se pica de estrellas vaga noctívaga húmida suple del ofertorio humeral

se recondena a una noche cerrada noche

se amordaza con un zurcido ocular

en las sombras los ojos que no ven

la bóveda celeste escomida en la botana sideral

fuera de órbita estrábica de las leyes

túrniase por alcanzar un os que la universe

recuesta imperforada

vulgata hostia intramuscular

norte pupilar de los meridianos magnéticos que navegan

el viaje de la noche

DIA 24

la noche se exhibirá

sólo para mayores de 21 años con carnet

rayos y truenos pasan raspando la noche

la noche se llena de aguas el manantial nocturno de la noche licúase la noche

fosforea perlada en sus átomos de agua

en la refriega de la noche

cuando la piel se le vuelve blanca como aurora

\section{EL DIA JUEGA AJEDREZ CON LA NOCHE}

pone el día sus piezas de luz en el recuadro oscuro de la noche pone la noche su perfil de ébano en el horizonte del día

se cuentan sus amorosas jugadas

sus estrategias de peón y reina 


\section{Álbum de Valparaíso. Santiago: Ed. LOM, 2002}

El mundo desembarcalen esta raya, día y noche.

Gonzalo Rojas. "Fundación de Valparaíso".

\section{Desembarco}

¿desembarco o desbarranco?

$$
\begin{aligned}
& \text { yo no avanzo metros } \\
& \text { entrometido en la métrica } \\
& \text { mis trancos son el blanco }
\end{aligned}
$$

$\begin{array}{ll}\text { salteador } & \text { pirata y leguleyo } \\ \text { alternativo } & \text { saltador de páginas }\end{array}$

$$
\begin{aligned}
& \text { me atrevo } \\
& \text { qué sé yo } \\
& \text { doro la perdiz }
\end{aligned}
$$

\section{Odiseo supo más por odiseo}

Con nudo ciego se amarró a los barrotes de la ventana cuando pasaron las Sirenas a eso de la hora 23.

Frente a su nariz se repeinaron, pusieron otra vez al rojo sus labios las bellas, estiraron sus medias por un infinito de piernas $y$ no se lo llevaron ni por los tacos

(¿En qué Era nos encontramos?)

Él ya cortaba las amarras para vengarse y hacerlas tragar semen. Pero también pensaba 
en una jugada popular y clásica: “¿Me puedes decir la hora, por favor?":

Finalmente se durmió sin darse. Y ellas se alejaron hacia la Zona de los Juegos Electrónicos.

Porque no soy argonauta despeluqué un vellocino. “¿Lo hiciste como se deshoja una vellorita, gachó?” me dice el coño.

Lo hice con la furia de los piratas asiáticos.

Lo hice con la simpleza de un hijo de vecino.

Lo hice porque nadie intervendría en la historia.

Al día siguiente desayuné ostras.

Refregué todo mi cuerpo con sal yodada y

he mantenido la lucidez hasta hoy.

Porque soy argonauta despeluqué un bello sino.

No estoy seguro.

\title{
Ya no me voy a sentar a la plaza me siento en la placilla
}

\author{
allí tomo sol \\ allí tomo sangre \\ allí escucho los retumbos que la tinta borra \\ y piso la borra que la tierra junta \\ tiro una colilla porque me da lo mismo \\ veo a las palomas mirarme con ojo de jote \\ y al carroñero venir a comer en mi mano
}


¿Una quijada de asno te ilumina la ampolleta?

Mi propia arenga no me impresiona

$$
\text { Termino por dormirme }
$$

\section{Suburbio de la bilis}

Caín, nuestro padre. El fundador de las ciudades.

José Emilio Pacheco

a tajo limpio

ni un mísero sentimiento oceánico

ni talentosa náusea

ni nada

hinchazón de jeta

jettatura

juego de la viroca

quítame esta paja

chaíto nomás 


\section{Object trouvé}

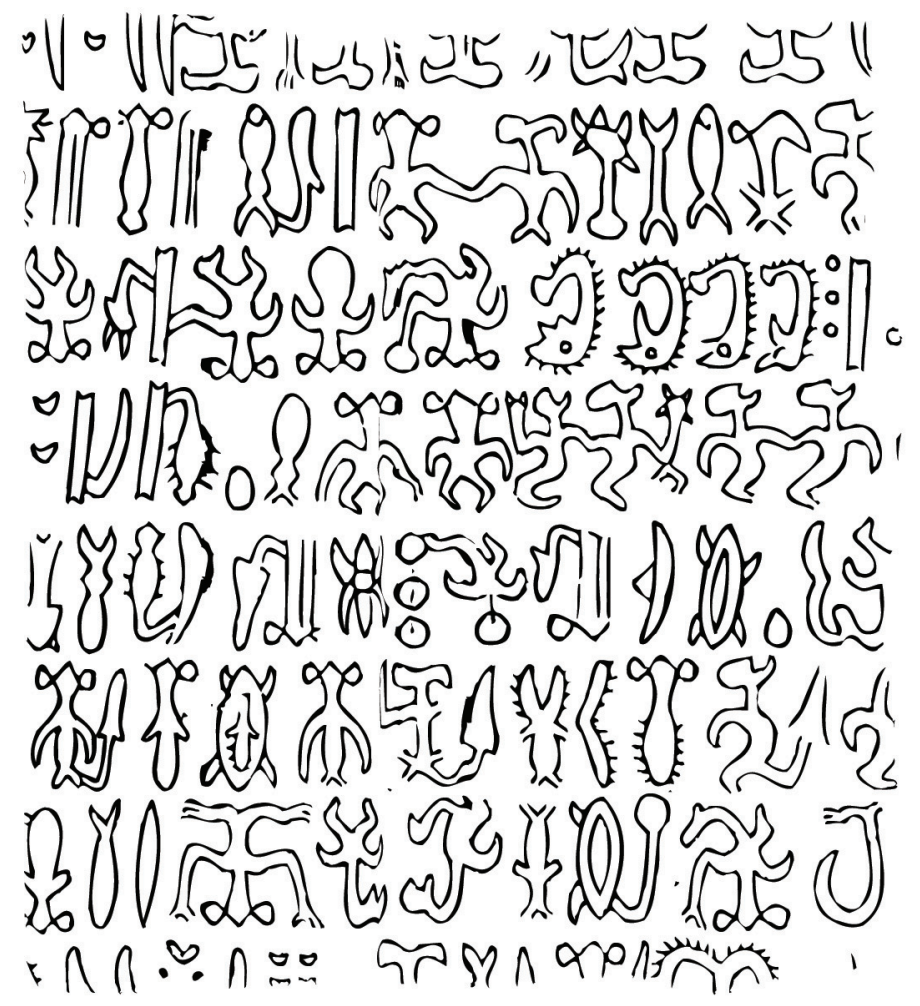

Si el caracol marino es un mar sinfónico estas páginas son milenios en silencio humano y su grito próximo.

ESCRITOS DEL VERANO DE 1992 
Cuaderno de deportes. Santiago. Ed. Cuarto Propio, 2010.

\section{ESCENARIO DE PAZ / ESCENARIO OLÍMPICO}

Las palabras - dardos que salen de la boca

tras un blanco indefinido. Salen

en cantidades industriales

cuasi plagas de langostas.

Muchas de ellas vienen muertas

otras no nacidas.

¿La paz? La silueta que no se recorta

ante los ojos de sus observadores.

Estamos en el corredor del espectáculo.

Al frente es la franja de Gaza.

\section{EMULACIÓN}

Aprende de la dirigencia

cuna del saber - se me abofetea.

Ellos ya pasaron por los cinco aros

a medio mundo. Ellos están embarcados.

Más bien ya llegaron

expertos en el remo de todas las aguas.

Tienen cancha tiro y lado

y aunque no logren sacar pecho

sacarán fuero y subirán al podio

por la razón o la fuerza.

Son gente muy especial.

Merecen premio. 


\section{CYBORG EN EL CAMINO}

Me encuentro con ella en la Vega Central.

Pudo competir en halterofilia

pero le robaron sus papeles

Dice que se siente como el cohete Rayo

impotente de atravesar la atmósfera.

En el aparcadero la conocen como "La Grúa".

Con sus enormes brazos

retira la carga más pesada de los camiones.

Cuenta que toda su familia

es burro de carga.

En confianza me habla

de sus implantes metálicos en los antebrazos.

Les da un par de sonoros besos.

Por ellos no le falta trabajo.

Sin embargo soltamos unos lagrimones

por el fin del ciclo agrario.

Después hacemos un brindis

para que la vida mantenga sus oportunidades.

\section{LIBRE COMPETICIÓN EN FUERZA Y VELOCIDAD}

A velocidad de tortuga me digo

camino de la contemplación.

Lo que transita por el mundo

tiene tanta disposición

que apenas le veo la nariz.

Como una pescadora del aire

me instalo a que algo pique.

Y nada de fuerza hercúlea 
me vuelvo a decir.

Golpes y encontronazos

abren menos que un parpadeo.

Me arrellano bajo un canelo.

32. TATUAJE

No luzco signos en mi piel

nada señalizo.

El agon - el juego y la lucha de la letra han llegado al hueso.

\title{
48. ANTIPRESEA
}

Mujeres del mundo como voceó Teresa Calderónnada de andar emparejando marcas.

Lo que está golpeando la puerta no va a dar ni para el bronce.

\section{EDIPO EN COLINA}

\author{
Amigos \\ a la sombra de Colina II \\ emergen más sombras \\ en los espacios interiores \\ de quien les habla.
}


Me tienen hasta más arriba

de la duramadre

estas patrañas de padre y señor mío

mentadas como verdades.

$\mathrm{Ni}$ el taller literario me consuela.

Este es el laberinto de Creta

yo su seguro servidor

y también la doncella.

\section{Amigos}

los abogados son poca luz.

Yo solo quiero saber

si el Destino puede ser rehabilitado.

Por favor

no me respondan a coro.

\section{EN BUSCA DE ACREDITACIÓN}

Escuchen, alguien viene llegando

con camas y petacas al hombro

con el ímpetu de la participación bajo el brazo

con la convicción de hacerse presente entre

ceja y ceja.

Viene de atrásmano

a destiempo

enrollado en carpetas

y una red explicativa.

Viene del país de Elich

donde todo se hace al revés. 